HeRvías Salinas, A., «La Ley 6/20I7, de 8 de mayo, de Protección del medio ambiente de La Rioja», REDUR I5,

diciembre 20I7, págs. I55-I73. ISSN I695-078X

\title{
LA LEY 6/2OI7, DE 8 DE MAYO, DE PROTECCIÓN DEL MEDIO AMBIENTE DE LA RIOJA
}

\author{
Agustín Hervías SALinAS \\ Doctorando del Programa de doctorado en Derecho y CAMbio Social \\ UNIVERSIDAD DE LA RIOJA
}

SUMARIO: I. Introducción. II. Antecedentes y tramitación de la Ley. III. Estructura y contenido. IV. Desregulación y simplificación administrativa. V. La intervención administrativa municipal en los procedimientos ambientales. Licencias ambientales y declaraciones responsables. V.r. Ámbito de aplicación de las autorizaciones ambientales municipales. V.2. La transitoriedad del Decreto 62/2006 en el procedimiento de concesión de las licencias ambientales. VI. Conclusiones.

RESUMEN: La necesidad de adaptación de la legislación riojana a la legislación básica estatal en materia de medio ambiente ha propiciado la redacción de esta nueva Ley, que entró en vigor el pasado i de junio, y que deroga la normativa en materia ambiental existente excepto el procedimiento de concesión de las licencias ambientales municipales, haciendo prácticamente una remisión en bloque a la Ley estatal para el resto de procedimientos, incorporando la figura de las declaraciones responsables.

Palabras Clave: Ley 6/20I7, protección medio ambiental, evaluación ambiental, licencias, declaración responsable

ABSTRACT: The need to adaptation the legislation in La Rioja to the State legislation with regards to the environmental aspects has led the drafting of this new law that went into effect on I June. This new law repeals the existing environmental regulation except the procedure on the grant of environmental licenses with municipal authorities, making practically a referral in block to the State law for all other procedures, introducing the form of responsible statement.

KEYWORDS: Law 6/20I7, environmental protection, environmental assessment, licenses, responsible statement.

\section{Introducción.}

El pasado I de junio entró en vigor la Ley 6/20I7, de 8 de mayo, de Protección del Medio Ambiente de la Comunidad Autónoma de La Rioja (en adelante, LPMAR). En ella, el legislador riojano hace una remisión prácticamente en bloque a la legislación básica estatal en materia tanto de prevención y control integrados de la contaminación como en lo referente a evaluación ambiental de planes, programas y proyectos. Relega a un posterior 
desarrollo reglamentario el procedimiento de concesión de las licencias ambientales, aplicándose de manera transitoria el establecido en el Decreto 62/2006 y en su anexo V. Como novedad, incorpora la figura de las declaraciones responsables de apertura con un claro espíritu de reducir las cargas administrativas en conexión con los principios de unidad de mercado, libre establecimiento y circulación.

La misma se elabora tras la entrada en vigor de las leyes 2I/20I3, de 9 de diciembre, de evaluación ambiental (en adelante, $\mathrm{LEA}^{2}$ ) y $5 / 2013^{3}$, de II de junio, cuyo carácter básico propiciaron la necesidad de revisar y adaptar la normativa autonómica en materia de protección ambiental, al amparo del título competencial establecido por el art. I49.I.23 $3^{\mathrm{a}}$ de la Constitución española (en adelante, CE) y de lo dispuesto en nuestro Estatuto de Autonomía.

El presente trabajo tiene por objeto el análisis de la estructura y contenido de la LPMAR, con una breve referencia a sus antecedentes, la simplificación administrativa introducida por la sucesiva normativa europea y un mayor detenimiento en el ámbito de aplicación de las licencias ambientales y de las declaraciones responsables de apertura, dentro del actual marco normativo.

\section{Antecedentes y tramitación de la Ley}

La Rioja no tenía, hasta la promulgación de la Ley 5/2002, normativa propia en materia medio ambiental, con la salvedad del Plan Especial de Protección del Medio Ambiente Natural de La Rioja (PEPMAN) de 30 de junio de I988, que estableció la obligación de someter a evaluación de impacto ambiental determinadas obras y actividades. Esta Ley 5/2002, configurada bajo las premisas del Real Decreto Ley 9/2000, de 6 de octubre, de modificación del Real Decreto legislativo I302/I986, de 28 de junio, de Evaluación de Impacto Ambiental, resultaba novedosa por cuanto que establecía aquellas obras, instalaciones o actividades que debían sujetarse al procedimiento de evaluación ambiental. Ya en el año 2006, se regula reglamentariamente su Titulo I, dedicado a la intervención administrativa, mediante la entrada en vigor del citado Decreto 62/2006, que concreta las previsiones sobre la evaluación de impacto ambiental de proyectos (no de planes y programas que se hizo a través del Decreto 20/2009), la autorización ambiental integrada y la licencia ambiental municipal. Posteriormente, la Ley 5/2002 se modifica

\footnotetext{
Decreto 62/2006, de io de noviembre, por el que se aprueba el Reglamento de Desarrollo del Título I, «Intervención Administrativa», de la Ley 5/2002, de 8 de octubre, de protección del medio ambiente de La Rioja.

${ }^{2}$ La LEA unificó la Ley 9/2006 sobre evaluación de los efectos de determinados planes y programas en el medio ambiente y el Real Decreto Legislativo I/2008, de is de enero por el que se aprobaba el Texto Refundido de la Ley de evaluación de impacto ambiental de proyectos.

${ }^{3}$ Ley 5/2013, de II de junio, por la que se modifican la Ley I6/2002, de I de julio, de prevención y control integrados de la contaminación y la Ley 22/20II, de 28 de julio, de residuos y suelos contaminados, hoy refundidos en Real Decreto Legislativo i/20i6, de I6 de diciembre, por el que se aprueba el Texto Refundido de la Ley de prevención y control integrados de la contaminación.
} 
sucesivamente desde $2003^{4}$, destacando como reformas significativas las operadas por la Ley 7/20I2, de 2I de diciembre, de medidas fiscales y administrativas de 20I3, la Orden I/20I3, de 22 de enero, del Consejero de Agricultura, Ganadería y Medio Ambiente, y la Ley Iо/2013, de 2I de octubre, de apoyo a emprendedores, autónomos y pymes, las cuales abordaremos más adelante.

Este proceso liberalizador ha tenido un impacto reducido en el Derecho ambiental, centrado en el mayor protagonismo de la comunicación previa como técnica de intervención administrativa de actividades de menor impacto ambiental. No obstante, las medidas legislativas han tendido con mayor o menor acierto a fomentar el crecimiento económico y permitir la libertad de implantación de actividades, como exponía la Directiva de Servicios 2006/ı23/CE, del Parlamento Europeo y del Consejo, de I2 de diciembre, (traspuesta a nuestro ordenamiento interno entre otras por la Ley Paraguas y la Ley Omnibus) la cual ya puso de relieve que para fomentar el crecimiento económico y la creación de empleo, resulta esencial un mercado competitivo de servicios, considerando que las normas de procedimientos administrativos no deben tener por objeto la armonización de los mismos, sino la supresión de regímenes de intervención administrativa previa que obstaculizan la libertad de establecimiento y la creación de nuevas empresas de servicios.

Como decíamos, dos normas básicas recientes, como son la Ley 5/2013, por un lado, y la LEA, por otro, han propiciado la redacción de la actual LPMAR adaptando ésta al marco normativo básico del Estado, en materia tanto de prevención y control integrados de la contaminación como en lo referente a evaluación ambiental de planes, programas, proyectos y actividades, con el espíritu de reducir las cargas administrativas. El proyecto de Ley nace mediante resolución del Consejero de Agricultura, Ganadería y Medio Ambiente de La Rioja de 2I de octubre de 20I4, con el fin de revisar y adaptar la normativa autonómica que desarrollaba el régimen de intervención administrativa en materia medio ambiental dentro del plazo del año que establece la Disposición Final $\mathrm{II}^{\mathrm{a}}$ de la $\mathrm{LEA}^{5}$ y que expiraba el I2 de diciembre de 20I4. Expresa la Resolución del Consejero que «la concertación en todo el territorio nacional de la normativa en materia de evaluación ambiental $Y$ de prevención y control integrados de la contaminación hace necesario derogar la LeY 5/2002 [...], Y formular una nueva haciendo una remisión en bloque a la normativa estatal en las materias anteriormente citadas, sin perjuicio de la regulación de aspectos concretos en materia competencial o procedimental».

La LPMAR tiene por objeto regular los regímenes de intervención administrativa y

\footnotetext{
${ }^{4}$ SANTAMARÍA ARINAS, R.J. «La Rioja: prohibición del fracking y retoques normativos a la espera de dos decisiones de la UNESCO», en LÓPEZ RAMÓN, F. (coord.), Observatorio de políticas ambientales, Pamplona, Thomnson-Reuters, 20I4, págs. 83I y ss.

Parcialmente declarada nula por la STC 53/20I7, de II de mayo, que resuelve el recurso de inconstitucionalidad interpuesto por la Generalitat de Catalunya, la cual no considera propio de la legislación básica los preceptos de la LEA que sean: a) Meras remisiones o reiteraciones de las reglas de procedimiento administrativo común o de las bases dictadas por el Estado ex art I49.I.I8 CE que no tengan especial vocación tuitiva del medio ambiente, y b) Las normas complementarias de aquellas que regulan los tramites esenciales de la evaluación ambiental, y que el TC considera que exceden el ámbito de lo básico, manteniéndose no obstante, el esquema procedimental común de la Ley (LozAno CuTANDA, B., «53/20I7, sobre la Ley de Evaluación Ambiental: se mantiene el esquema procedimiental común y se anulan o reinterpretan algunos preceptos», Actualidad jurídica ambiental, 7I, 20I7, págs. 8-23).
} 
los instrumentos de actuación sobre los planes y programas ambientales, los sistemas de gestión y auditoría así como los sistemas de garantía de calidad y la disciplina ambiental, estableciendo por una parte el régimen de inspección y por otro el sancionador. Bajo este prisma, se formuló el borrador de la Ley, que constaba de 57 artículos, estructurada en un título preliminar y tres títulos, una disposición adicional, dos transitorias, una derogatoria y dos finales.

El informe del Consejo consultivo de La Rioja (CcR) ha resultado ante este Proyecto de Ley menos crítico que el que se emitió ${ }^{6}$ con motivo de la Ley 5/2002, por la profusión de normativa europea que debía transponerse al ordenamiento interno y la diversidad legislativa que coexistía al momento de redacción de la ley riojana, sin que existiera referente anterior al respecto en materia de medio ambiente. La LPMAR no presenta una novedosa regulación de las actividades sujetas por la remisión procedimental que se hace al bloque estatal y por la renuncia del legislativo riojano a dictar normas sustantivas adicionales de protección.

El borrador del texto del anteproyecto fue sometido a información pública mediante su publicación en el Boletín Oficial de La Rioja de 4 de mayo de 20 I6 y en el Canal Participa del Gobierno de La Rioja. Se recibieron alegaciones por el parte del Colegio Oficial de Arquitectos de la Rioja, la Asociación Española de Fabricantes de Ladrillos y Tejas y de las distintas Direcciones Generales del Gobierno de La Rioja, destacando las formuladas por el Servicio de Urbanismo. Éste órgano alegaba que el borrador de la Ley no determinaba quien era el órgano sustantivo que debía resolver en cada caso, alegación que fue desestimada ya que resultaría difícil determinarlo. También se solicitó aclaración sobre si los ayuntamientos podrían seguir exigiendo licencia de apertura para las licencias comunicadas que no afectaran al medio ambiente, alegato que fue desestimado por cuanto que el artículo Io.4 resulta claro en su redacción. También fue objeto de reproche la simplificación del trámite de exposición pública del estudio ambiental estratégico en la elaboración del planeamiento municipal y en sus modificaciones, considerándose que tal cuestión deberá determinarse en fase reglamentaria de la Ley. A propuesta del citado Servicio de Urbanismo se incluyó una disposición transitoria tercera con el fin de clarificar el procedimiento de evaluación ambiental estratégica a seguir respecto del planeamiento y demás instrumentos de ordenación hasta que se apruebe el desarrollo reglamentario de la Ley, aspecto sobre el que incidiremos posteriormente.

Por la Dirección General de Salud Pública y Consumo se advirtió que, ante la entrada en vigor de la nueva Ley del Procedimiento Administrativo Común, que derogaba el Reglamento del Procedimiento para el Ejercicio de la Potestad Sancionadora, se reducía el plazo para la resolución del expediente sancionador de seis a tres meses, ampliando por ello la LPMAR en su artículo 48.5 a un año el plazo máximo para notificar la resolución expresa en los procedimientos sancionadores en materia de evaluación ambiental y autorización ambiental integrada, a contar desde el acuerdo de incoación, y a seis meses el seguido para

\footnotetext{
${ }^{6}$ Incluso se planteó por el CcR un reparo de inconstitucionalidad a propósito del artículo 9 de la Ley 5/2002 que declaraba exentas de control preventivo municipal las actividades de interés general de la Comunidad Autónoma de La Rioja.
} 
las licencias ambientales y las declaraciones responsables.

La memoria inicial del anteproyecto de la LPMAR asevera que la misma supone la completa adaptación de la legislación riojana al marco normativo básico del Estado español. No en vano, la exposición de motivos de la LEA establece que sirve como marco jurídico común para las CC.AA., sin necesidad de proceder por éstas a más modificaciones que las estrictamente necesarias, pero quienes podrán establecer, al amparo del I49.I.23 ${ }^{\mathrm{a}} \mathrm{CE}$, normas adicionales de protección del medio. El anteproyecto consta de 6I artículos, estructurados en un título preliminar y tres títulos, una disposición adicional, tres transitorias, una derogatoria y dos finales. En sede parlamentaria, el Proyecto de Ley entra en la Cámara el I6 de septiembre de 20ı6, emitiéndose informe por la Ponencia de 29 de noviembre del mismo año, integrada por tres miembros del Grupo Parlamentario Popular, dos del Grupo Socialista, un miembro por parte de Grupo Parlamentario Podemos y uno del Grupo Ciudadanos, no resultando las enmiendas al texto del calado técnico o jurídico que en otras iniciativas legislativas procede, llegando a la aprobación del Proyecto de Ley con 29 votos a favor y 3 abstenciones en sesión plenaria de 4 de mayo de 20I7, y publicándose el texto definitivo el I2 de mayo (BOR $\left.\mathrm{n}^{\circ} 54\right)$.

\section{Estructura y contenido}

La LPMAR, de aplicación a todos los planes, programas, proyectos instalaciones y actividades, de titularidad pública o privada susceptibles de producir efectos en el medio ambiente, la seguridad y la salud, se estructura en un Titulo Preliminar, donde se regulan las disposiciones generales en sus artículos del i al 8, incluyendo aquí el objeto, los fines, el ámbito de aplicación y las definiciones, destacando la remisión que a la Ley 27/2006, de I8 de julio, por la que se regulan los derechos de acceso a la información, de participación pública y de acceso a la justicia en materia de medio ambiente se hace para el ejercicio de estos derechos.

Le sigue el Título Primero, de intervención administrativa, donde se regula la evaluación ambiental estratégica y la evaluación de impacto ambiental, así como la autorización ambiental integrada, remitiendo en estos casos a la legislación básica, y se regula el sistema de licencias ambientales municipales, que deberá ampliarse reglamentariamente, subsistiendo en su procedimiento de concesión el Título IV del Decreto 62/2006 e introduciendo la declaración responsable de apertura, para los casos dispuestos en el apartado d) del artículo 9. Es este artículo noveno el que hace de piedra angular de la LPMAR, en cuanto al régimen de intervención, sometiendo de manera previa y con carácter ambiental el desarrollo de proyectos, instalaciones y actividades a uno o varios de entre los siguientes:

a) Evaluación ambiental, que seguirá el desarrollo previsto en la LEA para la evaluación ambiental estratégica de planes y programas o la evaluación de impacto ambiental para los proyectos que la requieran.

b) Autorización ambiental integrada, respecto de las actividades regladas en el Real 
Decreto Legislativo I/2016, de i6 de diciembre.

c) Licencia ambiental municipal, para aquellas actividades e instalaciones no incluidas en los dos supuestos anteriores, y para aquellos casos en que puedan ocasionar molestias y daños a las personas, bienes o al medio ambiente. Tampoco se requiere en los casos que fija la Ley I2/20I2, de 26 de diciembre, de medidas urgentes de liberalización del comercio y determinados servicios, cuando la superficie útil de exposición y venta al público sea igual o inferior a mil metros cuadrados, o en aquellos supuestos que, por estar por debajo de ciertos parámetros predeterminados en una orden aprobada por el titular de la Consejería competente puedan producir una escasa incidencia ambiental o en la salud. En este sentido, se abre nuevamente la puerta a que la Consejería (como sucedió con la Orden I/20I3, de 22 de enero, del Consejero de Agricultura, Ganadería y Medio Ambiente, por la que se exceptuaban de licencia determinadas actividades y servicios principalmente pecuarios) elabore un listado de actividades que, por su escasa incidencia en el medio, puedan requerir una modalidad de menor intervención administrativa. Los proyectos, instalaciones y actividades sujetos a evaluación de impacto ambiental y autorización ambiental integrada tampoco requerirán de licencia ambiental municipal.

d) Declaración responsable de apertura, que será exigible cuando sea necesaria la evaluación de impacto ambiental, la autorización ambiental integrada o la propia licencia ambiental municipal para la puesta en marcha del proyecto, la instalación o la actividad, salvo cuando la misma esté sujeta a licencia de primera ocupación conforme a la normativa urbanística. También opera esta declaración responsable de apertura en el sometimiento de las explotaciones ganaderas extensivas, incluida la apicultura, que no incluyan edificaciones, eximiéndolas así de la obtención de la licencia ambiental municipal.

Como novedad, se suprime la licencia de apertura, sin perjuicio de la exigibilidad de la licencia de primera ocupación, según lo dispuesto en el art Io.4 cuando sea preceptiva conforme a la normativa urbanística y al que más adelante nos referiremos.

En línea con la derogada Ley 5/2002, solo compete a la Administración local la concesión de la licencia ambiental, añadiendo ahora el control de las declaraciones responsables, y correspondiendo a la Comunidad Autónoma la evaluación de impacto ambiental, la autorización ambiental integrada y la evaluación ambiental estratégica de planes y programas. Conforme a lo dispuesto en el artículo io LPMAR, la evaluación de impacto ambiental y la autorización ambiental integrada precederán, en su caso, a la

\footnotetext{
${ }^{7}$ Por el que se aprueba el Texto Refundido de la Ley de prevención y control integrados de la contaminación, que integra la Ley $16 / 2002$, de I de julio, de prevención y control integrados de la contaminación, y las disposiciones en materia de emisiones industriales contenidas en normas con rango de Ley.

${ }^{8}$ La D.F. IO ${ }^{a}$ de la Ley I2/20I2 permite al legislador autonómico ampliar el umbral de superficie y el catálogo de actividades comerciales minoristas y de determinados servicios, realizados a través de establecimientos permanentes, situados en cualquier parte del territorio nacional, y cuya superficie útil de exposición y venta al público no sea superior a 750 metros cuadrados. La Ley 20/2013, de 9 de diciembre, de garantía de la unidad de mercado modificó tanto el artículo 2 ampliando de 300 a $750 \mathrm{~m} 2$ la superficie de exposición como la citada D.F. $\mathrm{IO}^{\mathrm{a}}$, permitiendo establecer regulaciones sobre estas mismas actividades con menor intervención administrativa, incluyendo la declaración de inocuidad, siendo objeto de recurso de inconstitucionalidad, al que luego nos referiremos.
} 
pertinente licencia de obras, estableciéndose la obligatoriedad de tramitar ahora conjuntamente la licencia ambiental y la correspondiente municipal de obras. Anteriormente, ex artículo 54.2 del Decreto 62/2006, la simultaneidad no era preceptiva, si bien la ambiental debía preceder siempre a la de obras de manera que la obtención de la segunda no podía producirse sin la consecución de la primera.

El articulo I3 LPMAR regula las modificaciones y los cambios de titularidad, estableciendo el sometimiento de la totalidad de la instalación o actividad al nuevo régimen de intervención administrativa cuando se produzca su modificación. Los cambios y ceses de actividad deberán ser comunicados en el plazo de un mes, y no en los tres meses que otorgaba la anterior Ley. Respecto del cese y la caducidad, aspecto de difícil concreción para las entidades locales con arreglo a la anterior normativa, la LPMAR no mejora estas previsiones, dejando en el lado del titular la obligatoriedad de comunicar el cese en el plazo de un mes, y considerando su caducidad (previa audiencia al interesado) cuando no se inicie la actividad en el plazo de dos años (salvo consideración en contra de la licencia ambiental) o se paralice por encima de esta fecha. Desde la esfera municipal, se deberá atender a lo dispuesto en las distintas Ordenanzas para determinar los efectos (sobre todo de ámbito fiscal) de los ceses de las actividades, pudiendo ahora, no obstante, declararse conclusa una actividad cuando supere el plazo de inactividad, plazo que anteriormente no regía. En línea con esto, se establece como novedad un plazo máximo de inicio de la ejecución de las instalaciones o actividades autorizadas, trascurrido el cual, la licencia otorgada perderá su eficacia.

El Titulo Segundo se refiere, al igual que lo hacía su predecesora, a los instrumentos de actuación, los sistemas de gestión y auditorías ambientales y los distintivos de garantía de calidad ambiental, reiterando el fomento de la etiqueta ecológica entre consumidores y empresarios. También se regulan aquí los instrumentos económicos, para la constitución de garantías, fianzas y cánones ambientales, previendo la continuidad del Fondo de Conservación Ambiental, cuya finalidad es proteger el medio ambiente y financiar actuaciones de prevención, protección, y restauración medioambiental, y que se nutrirá, según lo dispuesto en el artículo 42.2, de los Presupuestos Generales del Gobierno de La Rioja.

En manos de la Comunidad Autónoma quedan los instrumentos de desarrollo y ejecución de la política en materia de medio ambiente, con las finalidades de evitar o reducir la contaminación atmosférica, la carga contaminante de los vertidos a las aguas, la contaminación de los suelos o las que conduzcan a favorecer la reducción, la recuperación o el tratamiento de los residuos. En este sentido, cabe destacar el ya aprobado Plan Director de Residuos de La Rioja de 20i6. Bajo la nueva LPMAR, se halla en elaboración el Plan del Ciclo Integral del Agua, documento que integrará los futuros planes de abastecimiento, saneamiento y depuración a desarrollar en las seis cuencas riojanas para un periodo que comprende hasta el 2027.

No escapa al legislador la potestad recaudatoria como consecuencia de la prestación de servicios administrativos relativos a los procedimientos recogidos en la Ley, que devengarán sus correspondientes tasas y precios públicos, conforme a lo dispuesto en la Ley de Haciendas Locales como ingresos de Derecho público, incluyendo además la 
constitución de fianzas adicionales, a juicio del órgano sustantivo, para aquellas actividades cuyo funcionamiento comporte un riesgo potencialmente grave para el medio ambiente, en íntima conexión con el principio de quien contamina, paga y que responderán bien por las negligencias derivadas de la propia actividad o para restaurar el medio una vez producida la finalización de ésta si el promotor ignora su propio plan de desmantelamiento de la instalación.

El Titulo Tercero aborda en sus artículos 43 a 6r la disciplina ambiental, donde se otorga mayor protagonismo a la Administración local al revestir de autoridad a los funcionarios públicos que realicen actuaciones inspectoras, pudiendo acordarse la suspensión o la clausura del proyecto, obra, instalación o actividad cuando se oculten datos, se falseen o manipulen, o se incumpla con las condiciones ambientales impuestas, sin perjuicio de aplicar el régimen sancionador que corresponda. Este régimen sancionador, recogido en los artículos 47 y siguientes, distingue actuaciones para la evaluación de impacto ambiental y la autorización ambiental integrada (artículo 48) y el régimen sancionador para las licencias ambientales y las declaraciones responsables (artículos 49 y 50) remitiendo a la legislación básica el primer grupo y regulando con más detalle las infracciones del segundo grupo, que divide en muy graves, graves y leves, y las responsabilidades de los infractores, haciendo extensiva la obligación de reponer y la imposición de multas coercitivas reguladas para las licencias ambientales y las declaraciones responsables a las actuaciones punibles en materia de evaluación ambiental y de autorización ambiental integrada.

Los plazos de prescripción de las infracciones, recogidas en el artículo 52, para licencias ambientales y declaraciones responsables, son de tres años para las muy graves (cinco en la anterior Ley), dos años para las graves (tres en la anterior) y un año para las leves, pudiendo imponerse multas coercitivas y su ejecución subsidiaria, conforme a lo dispuesto en la normativa local y su exacción por la vía de apremio según el artículo 6r. Las sanciones que el órgano pueda imponer prescriben, conforme al artículo 54, en los mismos plazos (tres, dos y un año), computando el dies a quo desde el día siguiente a aquel en que adquiera firmeza la resolución sancionadora.

Concluye el texto legal con una disposición adicional única, tres disposiciones transitorias, una derogatoria y dos disposiciones finales. La D.A. permite el establecimiento de acuerdos voluntarios que fomenten la aplicación del principio de responsabilidad de los agentes económicos y sociales en la protección del medio ambiente, haciendo un llamamiento a la constitución de pactos políticos y empresariales en esta materia, para alcanzar un mayor nivel de protección que el legalmente establecido en los planes y programas públicos de ordenación territorial o en los relativos a sectores estratégicos o de protección ambiental.

La D.T. $\mathrm{I}^{\mathrm{a}}$ dispone la caducidad de actividades, instalaciones y proyectos que cesen temporalmente por espacio superior a dos años desde la entrada en vigor de la LPMAR. La D.T. $2^{a}$ prevé la sujeción a licencia ambiental de las actividades previstas en el anexo V del Decreto 62/2006, en tanto no queden sometidas a declaración responsable de apertura en virtud del artículo 9.2 d) LPMAR. Mayor detenimiento merece el contenido del apartado $2^{\circ}$ de la D.T. $3^{\text {a }}$, donde distingue los instrumentos de ordenación urbanística sujetos a 
evaluación ambiental estratégica ordinaria:

a) Las zonas de interés regional,

b) Los planes generales municipales,

c) Las directrices de actuación territorial, cuando no tengan por objeto la protección del medio ambiente, $y$

d) Los planes especiales que afecten a suelo no urbanizable, cuando no tengan por objeto la protección del medio ambiente o bienes de interés cultural.

Diferenciándolos en el apartado tercero de los que serán objeto de evaluación ambiental estratégica simplificada:

a) Las modificaciones del planeamiento urbanístico que afecten a suelo no urbanizable o a suelo urbanizable y de las que puedan derivarse afecciones significativas sobre el medio ambiente, previo informe del órgano ambiental.

b) Los planes de desarrollo de un planeamiento que no haya sido previamente sometido a evaluación ambiental estratégica.

c) Las directrices de actuación territorial, siempre que tengan por objeto la protección de medio ambiente.

d) Los planes especiales que afecten a suelo no urbanizable, que tengan por objeto la protección del medio ambiente o bienes de interés cultural.

La evaluación de estos planes y programas se hará, como hemos explicado anteriormente, conforme a la LEA. El apartado $4^{\circ}$ de la D.T. $3^{a}$ establece que, con carácter general, no será necesario realizar la evaluación ambiental estratégica, al considerarse que no producirán efectos ambientales significativos, de:

a) Las modificaciones de planeamiento en suelo urbano

b) Los proyectos de interés supramunicipal (sin perjuicio de sometimiento a evaluación de impacto ambiental)

c) Los Planes Especiales de Reforma Interior

d) Los estudios de detalle

e) Los planes de desarrollo de un plan que ya haya sido sometido a evaluación ambiental estratégica

f) Las Normas Urbanísticas Regionales

A este respoecto hay que tener en cuenta lo dispuesto, con carácter básico, en el artículo 6 LEA, donde se especifican los planes y programas sujetos a evaluación ambiental estratégica ordinaria, y que son aquellos que establezcan el marco para la futura autorización de proyectos sometidos a evaluación de impacto ambiental en determinados sectores como la agricultura, pesca, minería, gestión de residuos, telecomunicaciones... o requieran evaluación por afectar a espacios de la Red Natura 2000 y aquellos otros que deban ser sometidos a evaluación ambiental estratégica simplificada pero el órgano ambiental o el promotor decida someterlos a evaluación ambiental estratégica ordinaria. Quedan sujetos al régimen simplificado las modificaciones menores de los planes y programas citados, así como los planes y programas que establezcan el uso, a nivel municipal, de zonas de reducida extensión, y los que, estableciendo un marco para la autorización en el futuro de proyectos, no cumplan los anteriores requisitos. La sujeción a la 
evaluación ambiental encuentra su exención en aquellos planes y programas que tengan como objeto la defensa nacional o protección civil, y los de tipo financiero o presupuestario (artículo 8 LEA). Por tanto, la LPMAR parece que extralimita los supuestos que no deben ser objeto de evaluación ambiental estratégica, en contra de lo dispuesto en la normativa estatal y otorgando menor protección ambiental al grupo de planes y programas expuestos en el apartado cuarto de la D.T. $3^{a}$, lo que ha ocasionado que el Gobierno central, previo a la interposición del recurso de inconstitucionalidad, designe con el Gobierno autonómico un grupo de trabajo con la finalidad de evitar su interposición?. Tal exclusión va en contra de lo preceptuado en las distintas directivas comunitarias, que obligan a realizar una evaluación ambiental con carácter previo de todo plan, programa o proyecto que pueda tener efectos significativos sobre el medio ambiente estableciendo la presunción iuris et de iure de que, en todo caso, tendrán efectos significativos y por tanto deben ser evaluados antes de su aprobación, adopción o autorización, conforme al procedimiento ordinario. Para los restantes, cada Estado miembro deberá hacer un análisis para determinar los efectos sobre el medio, por el procedimiento simplificado, que derivará en el ordinario si el análisis concluye que tiene efectos significativos, garantizando así el correcto cumplimiento de las directivas de acuerdo con la interpretación del TJUE.

Que la LPMAR opte por el no sometimiento de los citados planes y programas con carácter general «al considerarse que no producirán efectos ambientales significativos«, implicará en la práctica que, de no modificar la D.T. $3^{\text {a }}$, la mayor parte de los instrumentos de planeamiento y de ordenación territorial queden exentos de evaluación y, sensu contrario, se deba justificar el sometimiento a evaluación ambiental estratégica de aquellos planes y programas en los que el órgano ambiental o el promotor así lo decida, resultando la generalidad favorecedora de los casos de exención de evaluación, en contra de la exposición de motivos de la LEA.

\section{Desregulación y simplificación administrativa}

Fruto de la pretendida flexibilidad administrativa e intervencionista y de la desregulación, con origen en la libre circulación y de servicios de la Unión Europea, a la que no fue ajeno el legislador riojano, surgieron en nuestro ordenamiento, modificando la Ley 5/2002, las siguientes normas:

- La Ley 7/20I2, de 21 de diciembre, de medidas fiscales y administrativas de 20I3, admitiendo la declaración responsable o la comunicación previa en sustitución de la licencia ambiental municipal con la redacción de los apartados 4 y 5 del artículo 25 de la Ley $5 / 2002$.

- La Orden I/2013, de 22 de enero, del Consejero de Agricultura, Ganadería y Medio Ambiente, eximiendo de licencia ciertas actividades de servicios y pecuarias,

\footnotetext{
${ }^{9}$ Por Resolución de II de septiembre de 20I7, de la Secretaria General de Coordinación Territorial, se publica el acuerdo de la Comisión Bilateral de Cooperación Administración General del Estado - CC.AA. de La Rioja en relación a la LPMAR, con el objeto de iniciar negociaciones para resolver las discrepancias manifestadas (BOE $n^{\circ}$ 233, pág. 94457, 27 de septiembre de 20I7).
} 
reemplazándola por la comunicación previa o la declaración responsable.

- La Ley Iо/2013, de 2i de octubre, de apoyo a emprendedores, autónomos y pymes, reduciendo el plazo administrativo para conceder la licencia ambiental de cuatro a tres meses e implantando el silencio positivo en caso de no resolución en plazo del expediente y posibilitando la puesta en marcha de actividades o instalaciones incluidas en capítulo IV del Título I de la Ley 5/2002, previa presentación de declaración responsable o comunicación previa.

Esta regulación, que pretendía la simplificación administrativa local en las citadas actividades (como ya hizo, por ejemplo, la Ley Vasca de Medio Ambiente en 20I2, enumerando las actividades sometidas a comunicación previa) no distinguía entre si el promotor debía declarar la apertura de la actividad o comunicar la realización de la misma, aspecto que ahora sí diferencia la LPMAR, adoptando la figura de la declaración responsable en su artículo 9.2 d) y desterrando la comunicación previa como modalidad de intervención.

La desregulación acometida por las normas expuestas, junto a la novedad de la inclusión de la declaración responsable como modalidad de intervención administrativa $a$ posteriori y sustitutoria de la licencia ambiental, permitirá la puesta en marcha de actividades e instalaciones que, por su escasa incidencia en el medio ambiente, no requieran de un control mayor, permitiendo así la desburocratización del sector económico entre pymes y autónomos, en la prestación fundamentalmente de sus servicios, como respuesta a los planes de recuperación y aceleración económica y a la demanda de creación de empleo puestos en marcha en el país. Es ahora sin embargo, donde debía producirse sin esperar al desarrollo reglamentario, la implantación de un procedimiento administrativo más ágil y con mayor grado de detalle de aquellas actividades que deben someterse a licencia o a declaración responsable. La proliferación legislativa vislumbra un escenario menos intervencionista en el ámbito municipal en relación a aquellas actividades, básicamente de servicios, que fomentan el empleo y el crecimiento económico, tanto en el entorno urbano como en el rural, pretendiendo eliminar los costes empresariales derivados de la fragmentación que subsiste en el mercado nacional y los obstáculos derivados del crecimiento de la regulación, potenciando las medidas liberalizadoras de la Directiva de Servicios y de las políticas de respuesta a la crisis económica, tras haberse iniciado el camino para la reducción del nivel de protección ambiental en beneficio de la reactivación económica ${ }^{\text {Io }}$.

En el ámbito estatal, cabe destacar en este sentido las novedades introducidas por la ya citada Ley I2/20I2, de 26 de diciembre y por la Ley 20/20I3, de 9 de diciembre, de garantía de la unidad de mercado (en adelante, LGUM). Ésta contiene dos mecanismos sustantivos para asegurar la unidad de mercado: la regulación de las técnicas para garantizar la libertad de establecimiento y circulación de las actividades económicas y el

\footnotetext{
${ }^{10}$ Pernas García, J.J. «Libre mercado y protección ambiental. De la ordenación administrativa de actividades económicas a la contratación pública verde», en LóPEZ RAMÓN, F. (coord.), Observatorio de políticas ambientales, Pamplona, Thomnson-Reuters, 20I4, págs. 433-437.
} 
establecimiento de la eficacia nacional de las decisiones adoptadas por las diferentes Administraciones públicas. Tal protección genera un efecto limitativo de la actividad económica actuando como excepción a la prohibición comunitaria de restricciones a las libertades de circulación, cediendo terreno ante la simplificación y desregulación administrativa, sintetizándose en la eliminación de regímenes autorizatorios y su sustitución por el régimen de comunicación previa, la supresión de límites temporales de las autorizaciones ambientales y la eliminación de los límites territoriales a las autorizaciones ambientales. No obstante, la reciente STC 79/20I7, de 22 de junio ${ }^{\text {II }}$, ha anulado aquellos preceptos de la LGUM que concedía esta validez extraterritorial de las autorizaciones, prevaleciendo así el necesario régimen de intervención autonómico de cada actividad o instalación que haya de autorizarse sobre el ya efectuado en otras regiones para la misma actividad, en contra de la preeminencia de la normativa de la autoridad de origen. La nulidad no alcanza sin embargo, a la pretensión de la recurrente, la Generalitat de Catalunya, de impugnar las modificaciones de la Ley I2/2012, de 26 de diciembre operadas por la LGUM, respecto de la menor intervención administrativa de actividades comerciales minoristas y la prestación de determinados servicios, conformes con que el Estado, en ejercicio de la competencia recogida en el artículo I49.I.I3 CE, promueva el objetivo económico de que se reduzcan las cargas administrativas para el acceso y ejercicio de una actividad económica. Si bien es cierto que la LGUM ha restringido la posibilidad de someter las actividades económicas a autorización, pues ésta sólo se podrá exigir por las concretas razones enumeradas en su artículo I7.I ${ }^{12}$, con ello la norma estatal no priva a las CC.AA. de poder «decidir políticamente fines $y$ orientar hacia ellos la regulación de una materia» ${ }^{\mathrm{13}}$ a través de la posibilidad de imponer restricciones materiales a esas actividades. Por tanto, la desregulación se ampara en el carácter básico de las normas, permitiendo a las autonomías el establecimiento de técnicas adicionales de control e intervención administrativa.

La Generalitat interpuso nuevamente recurso frente a determinadas disposiciones de la LGUM, que devino en la promulgación de la STC IIO/20I7, de 5 de octubre ${ }^{\mathrm{I}}$, anulando su artículo 6, sobre el principio de eficacia nacional de los medios de intervención. En el mismo sentido se articulaban los recursos de la Junta de Andalucía y del

\footnotetext{
${ }^{\text {II }}$ STC 79/20I7 de 22 de junio. Recurso de inconstitucionalidad I397-20I4. MP: Da. Encarnación Roca Trías.

${ }^{12}$ Art. I7.I LGUM: «Se podrá establecer la exigencia de una autorización siempre que concurran los principios de necesidad y proporcionalidad, que habrán de motivarse suficientemente en la Ley que establezca dicho régimen. [...] concurren los principios de necesidad y proporcionalidad para la exigencia de una autorización: a) Respecto a los operadores económicos, cuando esté justificado por razones de orden público, seguridad pública, salud pública o protección del medio ambiente en el lugar concreto donde se realiza la actividad, y estas razones no puedan salvaguardarse mediante la presentación de una declaración responsable o de una comunicación. b) Respecto a las instalaciones o infraestructuras físicas necesarias para el ejercicio de actividades económicas, cuando sean susceptibles de generar daños sobre el medio ambiente y el entorno urbano, la seguridad o la salud pública y el patrimonio históricoartístico, y estas razones no puedan salvaguardarse mediante la presentación de una declaración responsable o de una comunicación. [...] Las inscripciones en registros con carácter habilitante tendrán a todos los efectos el carácter de autorización».

${ }^{\mathrm{r} 3}$ F.J. $4^{\circ}$ de STC 4I/20I6, de 3 de marzo de 20I6. Recurso de inconstitucionalidad I792-20I4, interpuesto por la Asamblea de Extremadura en relación con diversos preceptos de la Ley 27/2013, de 27 de diciembre, de racionalización y sostenibilidad de la Administración local. MP: D Andrés Ollero Tassara.
}

${ }^{14}$ STC IIo/20I7. Recurso de inconstitucionalidad I4II-20I4. MP: D. Pedro José González-Trevijano Sánchez. 
Gobierno de Canarias, dando lugar a la recientes STC III/20I7, de 5 de octubre ${ }^{15}$ y la STC II9/20I7, de 3I de octubre ${ }^{\mathrm{r} 6}$, respectivamente, en las que, si bien se declaraba extinguido el recurso por perdida sobrevenida del objeto al ser resuelto en la anterior STC 79/2017, declara en la III/20I7 la nulidad del artículo 2I.I c) LGUM ${ }^{\text {I7 }}$. Como se aprecia, el espíritu iniciado con la Ley I7/2009, de 23 de noviembre, sobre el libre acceso a las actividades de servicios y su ejercicio, continuado con la Ley I2/20I2, de 26 de diciembre, y posteriormente con la LGUM, ha encontrado fundada oposición autonómica al entender las recurrentes invadidas sus competencias en la materia por parte del Estado, pero afianzando la corriente legislativa de desregulación y simplificación administrativa iniciada en la UE aplicable a las actividades minoristas e instalaciones, básicamente de servicios, que tengan escasa o nula incidencia en el medio y para las que la excesiva burocratización administrativa podía suponer un impedimento de cara a su implantación.

\section{La intervención administrativa municipal en los procedimientos ambientales. Licencias ambientales y declaraciones responsables}

V.r. Ámbito de aplicación de las autorizaciones ambientales municipales.

Bajo este escenario, donde las CC.AA. defienden sus competencias frente a la invasión por parte de la normativa básica del Estado, nace la LPMAR. Lo hace como consecuencia de dos aspectos importantes. Por un lado, para implantar los principios inspiradores del Derecho ambiental, como son el de acción preventiva, el principio de cautela, de responsabilidad ambiental o el de acceso a la información ambiental, que se unen a los ya conocidos de prevención y de quien contamina, paga, invocados en las sucesivas Directivas europeas. Por otro lado, como hemos expuesto, por la necesidad de materializar la nueva LPMAR conforme a la D.F. $\mathrm{II}^{\mathrm{a}}$ in fine de la LEA, haciendo una remisión prácticamente en bloque a la legislación básica estatal, y adaptando, tímidamente, el marco jurídico de las autorizaciones municipales a los nuevos criterios liberalizadores de la economía en relación a las actividades e instalaciones.

Procederá la exigibilidad de la licencia ambiental municipal como recogen los apartados c) y d) del artículo 9.2 LPMAR, en las actividades que no estén sujetas a evaluación de impacto ambiental o a autorización ambiental integrada, o que estén previstas

\footnotetext{
${ }^{15}$ STC III/20I7. Recurso de inconstitucionalidad I454-20I4. MP: D. Andrés Ollero Tassara.

${ }^{16}$ STC ir9/20I7. Recurso de inconstitucionalidad 5437-20I4. MP: D. Alfredo Montoya Melgar.

${ }^{17}$ Por el que las autoridades del lugar de fabricación serían las competentes para el control del cumplimiento de la normativa relacionada con la producción y los requisitos del producto para su uso y consumo, precepto contrario al principio de territorialidad de las competencias autonómicas en intima relación con el principio de eficacia nacional de los actos, disposiciones y medios de intervención de las autoridades competentes en el libre acceso y ejercicio de la actividad económica. En sectores como el turismo, asuntos sociales, servicios profesionales, medio ambiente, industria o agricultura, caza y pesca, etc., es frecuente encontrar en la normativa referencias explícitas al reconocimiento implícito de las actuaciones de otras autoridades competentes (llámese principio de eficacia nacional, de habilitación única, de colegiación única, etc.). La LGUM pretende hacer extensivo este principio, aceptado y aplicado con éxito en numerosos ámbitos, a todas las actividades económicas, pero finalmente ha sufrido su nulidad (art. 6) y la de sus art. I8.2 b), c) y e), I9, 20, 2I c), su D.A. Io y la modificación de la D.F. I
} 
en la Ley I2/20I2 o en la Orden I/20I3, siempre que sean susceptibles de causar molestias o daños a las personas, bienes o al medio ambiente, siendo también exigible para las actividades tasadas en el aún vigente Anexo V del Decreto 62/2006, de acuerdo con la transitoriedad prevista en la LPMAR.

Por el contrario, resulta exigible la declaración responsable de apertura en los

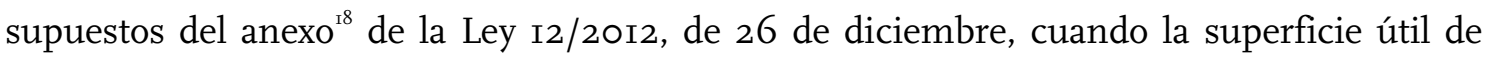
exposición y venta sea igual o inferior a mil metros cuadrados. Recordemos que legalmente se permitió que las CC.AA. aumentaran esta superficie establecida en la ley estatal, llegando a los mil metros en la LPMAR ${ }^{19}$. También resulta exigible en los casos en los que, a pesar de estar sujetas a licencia ambiental, puedan producir escasa incidencia en el medio ambiente o en la salud. Estos supuestos deben hallarse además, contemplados en una orden aprobada por la Consejería competente en materia ambiental, hito que puede reproducirse en el futuro por el titular de la Consejería donde radique la Dirección General de Calidad Ambiental $^{2 \circ}$, como sucedió con la Orden I/2013, de 22 de enero, que exceptuó de licencia ambiental las instalaciones de almacenamiento de combustibles para usos no industriales ni comerciales de menos de 300.000 litros de consumo medio anual y de 50.000 litros de almacenamiento, los aparcamientos subterráneos de uso privado en edificios de viviendas, las explotaciones pecuarias de autoconsumo y las de carácter no comercial con unos umbrales máximos de capacidad de animales por cada explotación. Añade ahora la LPMAR a la lista las explotaciones ganaderas extensivas, incluida la apicultura, que no incluyan edificaciones, cuando cumplan la legislación sectorial correspondiente.

Desde la esfera municipal, deberá atenderse a la especificidad de la actividad y a criterios bien de carácter técnico o de salubridad, e incluso urbanísticos, para sujetar a una u otra modalidad de intervención la actividad o instalación a implantar, esto es, para decidir si es merecedora de declaración responsable o de un nivel «superior» de intervención, como es la licencia ambiental. No debemos olvidar que el Anexo V del Decreto 62/2006 es anterior a las directivas europeas transpuestas al ordenamiento español que prevén una menor injerencia municipal en la implantación de determinadas actividades y servicios, por lo que procedimentalmente será complejo determinar la exigibilidad de una u otra modalidad de intervención en tanto en cuanto no dispongamos de la lista que posteriormente se fije por Consejo de Gobierno ex artículo 9.2 c).

${ }^{18}$ El anexo de la Ley recoge un número tasado de actividades principalmente de servicios (jurídicos, administrativos, educacionales, financieros ...) industria manufacturera, textil, del cuero y las instalaciones destinadas al comercio que, realizados a través de establecimientos permanentes, y cuya superficie útil de exposición y venta al público no sea superior a 750 metros cuadrados, pueden iniciarse mediante la presentación de una declaración responsable de apertura. El anexo fue modificado por la disposición final 7.2 de la Ley I4/20I3, de 27 de septiembre, de de apoyo a los emprendedores y su internacionalización.

${ }^{19}$ En este sentido se pronunció, por ejemplo, la Dirección General de Innovación y Energía en el trámite de audiencia de la LPMAR, por la contradicción entre el Anexo de la Ley I2/2012 de 26 de diciembre y el correspondiente al Decreto 62/2006, siendo deseable determinar los supuestos de aplicación al régimen de licencia o de declaración responsable por el objeto de la actividad y/o la superficie útil de exposición y venta.

${ }^{20}$ Por Decreto $28 / 2015$, de 2I de julio, por el que se establece la estructura orgánica de la Consejería de Agricultura, Ganadería y Medio Ambiente y sus funciones en desarrollo de la Ley 3/2003, de 3 de marzo de organización del Sector Público de la Comunidad Autónoma de La Rioja, la competencia recala en la actualidad en el Sr. Consejero de Agricultura, Ganadería y Medio Ambiente. 
La LPMAR determina también la exigibilidad de la declaración responsable de apertura para el inicio de actividades sujetas a evaluación de impacto ambiental, autorización ambiental integrada o licencia ambiental. No resulta necesaria sin embargo la declaración responsable cuando la instalación quede sujeta a licencia de primera ocupación de conformidad con la normativa urbanística. Ésta es la que tiene por objeto controlar la adecuación de lo construido a lo proyectado, verificando asimismo si el edificio reúne las condiciones de seguridad y salubridad precisas (en este sentido, $v d$. STS de 8 de noviembre de 2003, o STSJ de La Rioja de 26 de junio de 2007). Ambas licencias, de apertura y de primera ocupación, son independientes, autónomas y plenamente compatibles, trasladando al administrado la responsabilidad y competencia municipal de comprobación de lo ejecutado conforme a lo proyectado, y difiriendo de la licencia de apertura, que es la que ejerce un control preventivo sobre lo que el interesado ha proyectado y pretende ejecutar, gozando de un carácter previo, y que la LPMAR suprime. Al no ser de obligada obtención la licencia de ocupación, una vez obtenida la licencia ambiental y la de obras, la declaración responsable de apertura sirve para comenzar la actividad. La normativa urbanística no dispone numerus clausus los casos en los que es preceptiva la licencia de primera ocupación, siendo a criterio del promotor su necesidad de obtención, en función del destino del inmueble. Luego, una actividad sujeta a licencia ambiental, no requerirá de otra autorización administrativa para el desempeño de su actividad que la mera presentación de la declaración responsable de apertura, ya que la legislación no le exige la obtención de la pertinente licencia de primera ocupación. En sentido contrario se expresa el actual Real Decreto Legislativo 7/2015, de 30 de octubre, por el que se aprueba el texto refundido de la Ley de Suelo y Rehabilitación Urbana, cuando en su artículo ir.5, establece: «Cuando la legislación de ordenación territorial y urbanística aplicable sujete la primera ocupación o utilización de las edificaciones a un régimen de comunicación previa o de declaración responsable [...]», invirtiendo la autorización administrativa de primera ocupación en favor de una comunicación o declaración, no constituyendo éstas, en puridad, una auténtica modalidad de intervención.

En otras regulaciones autonómicas, la declaración responsable no atiende al paso previo de habilitación ambiental como recoge nuestra LPMAR, sino que las obras necesarias para la actividad deben ser anteriores. Destaca aquí la declaración responsable de la Ley $6 / 2014$, de 25 de julio, de prevención, calidad y control ambiental de actividades en la Comunitat Valenciana, donde en su artículo 68 establece que: «Con anterioridad a la presentación ante el ayuntamiento de la declaración responsable ambiental, los interesados deberán haber efectuado, de acuerdo con lo establecido en la normativa en vigor, las obras e instalaciones eléctricas, acústicas $y$ de seguridad industrial $y$ demás que resulten procedentes en función de la actividad a desarrollar». Las obras pueden ser anteriores en la Región de Murcia, según su Ley 4/2009, de I4 de mayo, de protección ambiental integrada, artículo 70.I: «La declaración responsable de actividad podrá presentarse una vez concluidas las obras $Y$ las instalaciones necesarias». 
V.2. La transitoriedad del Decreto 62/2006 en el procedimiento de concesión de las licencias ambientales.

La transitoriedad que hemos venido resaltando a lo largo de este análisis del título IV (artículos 55 a 62) del Decreto 62/2006 producida por mor de la disposición derogatoria única de la LPMAR: «Queda derogada [...] b) El Decreto 62/2006, de 10 de noviembre [...] excepto el procedimiento administrativo regulado en el título $I V$, referido a la concesión de la licencia ambiental $y$ el anexo $V . . . »$ produce la reviviscencia del procedimiento para el otorgamiento de las licencias ambientales, impidiendo la desregulación administrativa y simplificadora que la LPMAR pretende, hasta que reglamentariamente se desarrolle la misma.

Por esto, si el procedimiento administrativo referido a la concesión de la licencia ambiental permanece vigente conforme al Decreto 62/2006, ¿podremos aplicar el procedimiento homónimo establecido en la LPMAR en la resolución de las licencias ambientales? ¿O solo cuando uno no contravenga al otro? ¿Qué plazos rigen? ¿Y cómo entenderá el administrado el silencio producido? Para dar solución a este problema de aplicación, debemos acudir, en primer lugar, al artículo i28 LPAC, que establece que los reglamentos y disposiciones administrativas no podrán vulnerar la Constitución o las Leyes. En segundo lugar, es sabido que las disposiciones administrativas de carácter general se ajustan a la siguiente jerarquía normativa: $I^{\circ}$ Decretos; $2^{\circ}$ Órdenes acordadas por las Comisiones Delegadas del Gobierno; $3^{\circ}$ Órdenes Ministeriales; $4^{\circ}$ Disposiciones de autoridades y órganos inferiores y considerar que deberá darse prioridad en la aplicación a las leyes elaboradas posteriormente y aplicar las ya existentes en tanto en cuanto no contravengan a aquéllas, bajo el aforismo lex posterior derogat priori.

En este caso, el Título IV del Decreto 62/2006 está facultado por la disposición derogatoria única de la LPMAR, norma con rango de ley, y las actividades del Anexo $\mathrm{V}^{2 \mathrm{I}}$ por su disposición transitoria $2^{\text {a: }}$ : [...] estarán sujetas a licencia ambiental, salvo que la actividad, instalación o proyecto quede sujeta a la declaración responsable de apertura en virtud de lo establecido en la presente ley», pero no establece una transitoriedad sobre el plazo de resolución o el sentido del silencio fijado en el Decreto. No obstante, hemos convivido con una pluralidad de disposiciones en lo referente a la implantación de actividades e instalaciones, promovidas por la pretendida simplificación administrativa. A modo de ejemplo, el artículo 9.5 de la Ley 10/2013 establece que «La falta de resolución en plazo por parte de la Administración, de los procedimientos relativos a la creación e instalación de empresas, tendrá efectos estimatorios, excepto en los supuestos en los que una norma de derecho comunitario o una norma con rango legal contenga una justificación explícita que ampare el efecto desestimatorio del silencio administrativo por razones imperiosas de interés general» dejando

\footnotetext{
${ }^{21}$ Los anexos del Decreto 62/2006 se habían limitado a transcribir literalmente las listas estatales de proyectos sometidos a evaluación de impacto ambiental, alteradas por la reforma de 2013 para, en algún caso, añadir alguna actividad nueva como el fracking por ejemplo, -actividad del Anexo I del grupo 2.7 d) de la Ley 2I/20I3, sometida a la evaluación ambiental ordinaria- pero también, para rebajar el grado de protección. SANTAMARÍA ARINAS, R.J., «La Rioja: el desplazamiento, que no derogación de la normativa autonómica sobre evaluación ambiental de planes y programas», en López RAMÓn, F. (coord.), Observatorio de Políticas Ambientales, Madrid, editorial CIEMAT, 20I7, págs. 949 y ss.
} 
abierta la denegación de la licencia ambiental que por motivos de salud pública o daños al medio ambiente y de manera motivada, se considere susceptible de ello. El contenido de esta Ley, por ser contraria a la posterior LPMAR, carecerá de vigencia aunque no haya sido expresamente derogada. Igual ocurre con el plazo de cuatro meses que el Decreto 62/2006 destina a la resolución de la licencia ambiental en su artículo 59.I, el cual, por jerarquía normativa, queda derogado por la LPMAR, que reduce a tres meses el plazo de resolución. El artículo 9.4 de la Ley Iо/20I3 había reducido ya a tres meses el plazo de resolución «para la implantación de una actividad económica a los que se refiere la disposición final primera». También la D.A. I ${ }^{a}$ de la misma, que modificó la Ley 5/2002, alteró el sentido del silencio, pasando a ser positivo, como se recoge en su artículo 9.5: «La falta de resolución en plazo por parte de la Administración, de los procedimientos relativos a la creación e instalación de empresas, tendrá efectos estimatorios...» entendiendo el solicitante estimada la solicitud en caso de no caer resolución expresa, para el listado de actividades que se iba a aprobar en virtud de su disposición final: «El Gobierno de La Rioja, en el plazo de tres meses desde la entrada en vigor de esta ley, aprobará una relación detallada de los procedimientos y trámites relacionados con la creación e instalación de empresas», listado que no consta que se llegara a elaborar.

Este esquema procedimental chocaba con el vigente artículo 59.I del Decreto 62/2006, donde «La Resolución deberá dictarse en el plazo máximo de cuatro meses [...]. Transcurrido el plazo [...] se entenderá denegada» quedando desplazado el Decreto 62/2006 en favor de la citada Ley. También ahora se produce tal enfrentamiento con las disposiciones de la LPMAR en cuanto al plazo y en lo que respecta a la exigibilidad de la licencia de apertura, puesto que el artículo 59.4 del Decreto 62/2006 añade que: «Otorgada la licencia ambiental y las demás que fueran pertinentes, no podrá comenzar a ejercerse la actividad ni funcionar la instalación hasta tanto se haya obtenido la licencia de apertura, a efectos ambientales».

A modo de ejemplo, una solicitud para la obtención de la licencia ambiental dirigida al Alcalde del Ayuntamiento donde radique la actividad o instalación, se resolverá, si no se encuentra dentro de los supuestos del artículo 9.2 d) LPMAR de declaración responsable de apertura (ex D.T. $2^{a}$ LPMAR) en un plazo máximo de tres meses, y el silencio, en caso de no resolverse expresamente, será negativo (como establece el artículo 2I LPMAR) entendiéndose desestimada la solicitud, desplazando las disposiciones del Decreto 62/2006 en cuanto al plazo de resolución y de la Ley Io/2013 respecto del silencio producido, por contravenir lo dispuesto en la LPMAR, con la obligatoriedad de tramitar ahora conjuntamente la licencia ambiental y la correspondiente municipal de obras, en su caso.

Expuesto lo anterior, la nueva LPMAR debería haber concretado el esquema de tramitación de las licencias ambientales antes de dotar de transitoriedad al procedimiento establecido en el Decreto 62/2006, a la luz de las discrepancias normativas existentes. Sin perjuicio de desarrollo reglamentario posterior del procedimiento de concesión de las licencias ambientales, ha perdido el legislador riojano ahora la oportunidad de:

a) Simplificar y detallar el procedimiento de licencias ambientales, por la reviviscencia que hace del Título IV del Decreto, y de su Anexo V, debiendo esperar al 
desarrollo reglamentario de la LPMAR para conocer el listado de actividades que sustituirán a actual Anexo $\mathrm{V}^{22}$, derogando expresamente el elenco de disposiciones que contradicen a las de la nueva Ley.

b) Dotar de mayor protección a las actividades e instalaciones sujetas a otros tipos de intervención administrativa, para las que hace una remisión en bloque a la LEA.

c) Regular aquellas actividades que, por su escaso impacto o incidencia ambiental, quedarían sujetas a comunicación previa o declaración responsable.

d) Someter expresamente a evaluación ambiental estratégica aquellas figuras de planeamiento y ordenación territorial que con carácter general exime, en contra de las directivas europeas y de la propia LEA.

Al igual que ocurrió con la postura adoptada por la Administración pública riojana al presumir la oposición total y absoluta del Decreto 20/2009 $9^{23}$ a la LEA, conviniendo la «derogación» del primero desde el I2 de diciembre de 2014 (fecha de entrada en vigor de la LEA) y decidiendo aplicar ésta a todos los planes y programas cuya evaluación ambiental se iniciase a partir de esa fecha, ahora el legislativo provoca la vigencia de dos procedimientos administrativos para la intervención administrativa municipal lo que hace que la entrada en vigor de la LPMAR sea meramente instrumental por, como decíamos, ser una ley de remisión al cuerpo estatal y carente de aportaciones propias en lo referente a evaluación ambiental y autorización ambiental integrada, y haber quedado confusa la regulación de las licencias ambientales y escasa y dispersa la de los supuestos sujetos a declaración responsable.

\section{Conclusiones}

En definitiva, la necesidad de adaptar la legislación riojana en materia ambiental, junto con la incipiente aparición de nuevas formas de actividad comercial y la necesidad de dotar de mecanismos ágiles de establecimiento, ha obligado al legislador a regular aquellos usos y actividades que deben ser objeto de intervención administrativa por una u otra técnica procedimental. No ha debido hacer, a nuestro juicio, la remisión en bloque a la normativa estatal para aquellas propuestas de mayor calado e impacto en el medio sin proponer mayores técnicas de protección para los proyectos y actividades sujetos y ha dejado escapar el control sobre instrumentos de planeamiento y ordenación del territorio que, sin duda, deberá contemplar tras la controversia aflorada con la disposición transitoria tercera para el futuro sometimiento a evaluación ambiental de determinados planes y programas.

\footnotetext{
${ }^{22}$ El Anexo V regula numerus clausus las actividades sometidas a licencia ambiental, añadiendo aquellas que no alcancen los umbrales previstos para la obtención de autorización ambiental integrada o de evaluación de impacto ambiental y que se agrupan en actividades turísticas y recreativas, actividades agrarias, alimentarias y pecuarias, y actividades industriales.

${ }^{23}$ SAnTAmaría ArinAS, R. J., «La ley de ordenación del territorio y urbanismo de La Rioja: rumbo a la sostenibilidad tras una década marcada por la crisis económica», Revista de Práctica Urbanística, I43, 20I6, págs. $9 \mathrm{I}-\mathrm{9}^{2}$.
} 
La LPMAR no llega a determinar con claridad los supuestos de aplicación al régimen de licencia ambiental o de declaración responsable $\mathrm{y}$, a pesar de prever el desarrollo reglamentario de la misma para definir el estadio final de protección medioambiental en La Rioja, debió matizar los supuestos de sujeción a una $u$ otra modalidad, evitando trasladar a la esfera municipal tanto el desarrollo del contenido de la declaraciones responsables y las comunicaciones previas mediante la oportuna Ordenanza municipal, como el control sobre aquellas actividades e instalaciones a implantar y la fiscalización de su correcto cumplimiento para la preservación de nuestro medio ambiente. Establece el instituto de las declaraciones responsables para una terna dispersa e insuficiente de supuestos, haciendo desaparecer la licencia de apertura. En el ámbito de las licencias ambientales, la simplificación administrativa pretendida se encuentra en suspenso al coexistir una pluralidad de normas que se solapan y que complican la técnica procedimental en la esfera municipal.

Ha perdido el legislador la oportunidad de regular con mayor detalle el ámbito y los efectos de la transmisibilidad de las licencias, que merece un apartado más profundo dentro de la Ley, y matizar los efectos de los supuestos de cese y suspensión de las actividades.

No obstante, la LPMAR cumple con la premisa establecida por el Sr Consejero en su resolución de 2014 y que sirvió para su elaboración de «formular una nueva haciendo una remisión en bloque a la normativa estatal sin perjuicio de la regulación de aspectos concretos en materia competencial o procedimental». 